\title{
Prevalence of iron and folic acid supplements consumption and associated factors among pregnant women in Eswatini: a multicenter cross-sectional study
}

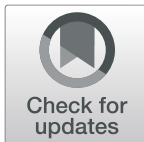

\author{
Gugulethu N. Mabuza', Alexander Waits ${ }^{1,2,3}$, Owen Nkoka $^{4}$ and Li-Yin Chien ${ }^{1,5^{*}}$
}

\begin{abstract}
Background: During pregnancy, nutritional requirements increase and if not met, pregnancy-related complications may manifest. To prevent these undesirable outcomes, the World Health Organization recommends daily oral iron and folic acid (IFA) supplementation as part of antenatal care. Despite this recommendation, the use of IFA supplements is still very low in several developing countries. Additionally, no prior information exists regarding the level of consumption of IFA in Eswatini. Thus, this study aimed to determine the prevalence of consumption of IFA supplements and to identify factors associated with the consumption of IFA supplements among pregnant women in Eswatini.
\end{abstract}

Methods: A cross-sectional questionnaire survey was conducted among 330 pregnant women aged $\geq 18$ years in their third trimester in Eswatini. Participants were recruited from eight purposively selected healthcare facilities from July 2019 to October 2019. Good consumption was defined as consuming all or almost all IFA supplements throughout pregnancy.

Results: During the first trimester, $10.3 \%$ of the participants consumed all or almost all IFA supplements. In the second and third trimesters, those who consumed all or almost all supplements were 37 and $39.7 \%$, respectively, for iron and 37.6 and $40.9 \%$, respectively, for folic acid. Barriers, including side effects, forgetfulness, safe previous pregnancies without IFA, others' advice against consumption, IFA stock-outs, inability to meet transport costs, and inadequate supply of IFA tablets, contribute to low consumption of IFA. Multivariate logistic regression models showed that the barriers were inversely associated with good consumption of IFA supplements. Better knowledge and attitude toward IFA and older maternal age were positively associated with good consumption of IFA supplements.

\footnotetext{
* Correspondence: lychien@nycu.edu.tw

'International Health Program, National Yang Ming Chiao Tung University, 155 Li-Nong Street, Section 2, Bei-Tou, 11221 Taipei, Taiwan

${ }^{5}$ Institute of Community Health Care, College of Nursing, National Yang Ming Chiao Tung University, 155 Li-Nong Street, Section 2, 11221 Taipei, Taiwan

Full list of author information is available at the end of the article
}

C The Author(s). 2021 Open Access This article is licensed under a Creative Commons Attribution 4.0 International License, which permits use, sharing, adaptation, distribution and reproduction in any medium or format, as long as you give appropriate credit to the original author(s) and the source, provide a link to the Creative Commons licence, and indicate if changes were made. The images or other third party material in this article are included in the article's Creative Commons licence, unless indicated otherwise in a credit line to the material. If material is not included in the article's Creative Commons licence and your intended use is not permitted by statutory regulation or exceeds the permitted use, you will need to obtain permission directly from the copyright holder. To view a copy of this licence, visit http://creativecommons.org/licenses/by/4.0/. The Creative Commons Public Domain Dedication waiver (http://creativecommons.org/publicdomain/zero/1.0/) applies to the data made available in this article, unless otherwise stated in a credit line to the data. 
Conclusions: Low consumption of IFA supplements in overall pregnancy is mainly owing to the late antenatal care attendance. Strategies such as establishing a preconception care unit and school-based provision of IFA may be helpful. It is evident that most women still lack knowledge, and some have negative attitudes about IFA supplements. Health education to raise awareness and emphasize the importance of starting antenatal care early as well as consuming supplements on time should be revisited and intensified. Multiple strategies such as including community health care workers for distributing IFA supplements, discussing with clients about the measures to reduce forgetfulness, advising ways to prevent and manage the side effects, providing subsidies to cover transport costs, and ensuring adequate supply of IFA supplements in facilities may need to be employed to reduce the identified barriers.

Keywords: Iron and folic acid supplements, Associated factors, Pregnant women, Eswatini

\section{Background}

Nutritional requirements increase during pregnancy for supporting fetal growth and development as well as for maternal metabolism and tissue development specific to reproduction [1]. The recommended dietary allowance for iron and folic acid (IFA) for non-pregnant women is $18 \mathrm{mg}$ and $400 \mu \mathrm{g}$ [2] when compared with $27 \mathrm{mg}$ and $600 \mu \mathrm{g}$ per day for pregnant women [3], respectively. If the required increase in dietary allowance is not met, numerous undesirable conditions may manifest. Folate deficiencies have been linked to the development of neural defects in infants [4], and iron deficiencies have been linked to anemia and other conditions.

The average prevalence of anemia among pregnant women in developing countries is $56 \%$, which is significantly higher than that of $18 \%$ in developed countries. In Africa, the prevalence of anemia in pregnant women is $48.2 \%$ [5]. In Eswatini (a country in Southern Africa), $31 \%$ of pregnant women fall under the classification of maternal anemia [6], although the possible reasons for the lower prevalence in Eswatini when compared with other developing countries have not been studied. Anemia is one of the major causes of pregnancy complications, leading to adverse maternal and perinatal outcomes, including maternal and perinatal mortalities [7]. Anemia in pregnancy is highly associated with the risk of miscarriages, stillbirths, prematurity, and low birth weight [8]. It is estimated that $40 \%$ of women in Eswatini are likely to be anemic, which may be owing to insufficient iron [9]. It is also estimated that 300,000 babies are born each year with neural tube defects globally, and $15-20 \%$ of all births are low birth weight. The 2014 Swaziland Multiple Indicator Cluster Survey indicated that $8 \%$ of infants had low birth weight [10]. To prevent and cure these outcomes, the World Health Organization (WHO) strongly recommends daily oral supplementation of IFA as part of antenatal care (ANC). Studies conducted in different countries have shown that the use of IFA early and during one's pregnancy can reduce undesirable pregnancy outcomes [11-13]. In Eswatini, the ANC package, which includes the provision of
IFA, has been made accessible and affordable to every pregnant woman.

Despite the WHO recommendation, the use of IFA is still low in some developing countries. Adherence to iron supplementation across 22 Sub-Saharan African countries was $28.7 \%$, with some countries having low adherence, such as $1.4 \%$ in Burundi [14]. Another study in Northern Tanzania revealed that the prenatal intake of folic acid and iron supplements by pregnant women was 17.2 and $22.3 \%$, respectively [15]. Nonetheless, the consumption of IFA was reported to be $93 \%$ in South Africa [16]. To the best of our knowledge, there is no prior study on the consumption of IFA supplements among pregnant women in Eswatini.

The factors associated with poor consumption in countries such as Ethiopia and Egypt include lack of IFA supplements owing to not getting enough supplements to last until the next visit, forgetfulness, side effects of oral medications, little knowledge about the importance of supplements, and poor knowledge of anemia in pregnancy $[8,17]$. In Eswatini, the problem of medication stock-outs is also common. At some point, the country's local daily newspaper published that the country had run out of essential drugs for pregnant women [18].

According to several studies, the following factors are associated with good IFA consumption: more ANC visits, early ANC booking, counseling and education on IFA supplements, higher levels of education, diagnosis of anemia in a previous ANC visit, exposure to mass media, and presence of husbands during ANC visit [19-22]. Poor consumption arises not only because of the client's behaviors but also because of factors outside the client's control [23]. Such factors may include inadequate support from significant others and/or families and insufficient service delivery. Other client factors may include frustrations about the number and frequency of the pills, fear of macrosomia, etc. [24]. Limited information has been gathered regarding the level of consumption of IFA and related factors in Eswatini. Thus, this makes such a study a necessity. This study aimed to determine the consumption of IFA supplements, to explore IFA-related barriers, knowledge, and attitude, and to determine the 
factors associated with the consumption of IFA supplements among pregnant women in Eswatini.

\section{Methods \\ Setting}

The study was conducted in eight health care facilities that were selected to represent the four regions of Eswatini; each region was represented by two facilities. The facilities were Mbabane Government Hospital and Lobamba Clinic in the Hhohho region, Raleigh Fitkin Memorial Hospital and Family Life Association of Swaziland in the Manzini region, Sithobela Health Centre (Maternity unit) and Sithobela Public Health Unit in the Lubombo region, and Hlathikhulu Public Health Unit and Hlathikhulu Hospital (maternity unit) in the Shiselweni region. The eight health facilities were selected purposively, as these institutions provide ANC services and have high volumes of clients in the regions.

\section{Study design and participants}

This study used a cross-sectional questionnaire survey design. The inclusion criteria were pregnant women aged $\geq 18$ years, residing in Eswatini, in their third trimester, and visiting for a subsequent ANC at the eight selected health facilities. Participants $<18$ years were not included because they needed parental consent to participate. We selected third-trimester pregnant women because we were interested in comparing IFA consumption across different trimesters. It seems to be easier for third-trimester pregnant women to recall their IFA consumption than postpartum women. Besides, a high use rate of any antenatal care $(97.3 \%)$ was reported in Eswatini [25]. Therefore, we expected a high coverage rate of antenatal care among third-trimester pregnant women. During the period from July 2019 to October 2019, 330 women were invited to participate in the study; they all agreed to participate.

\section{Ethics approval and consent to participate}

This study was approved by the National Health Research Review Board, Ministry of Health, in Eswatini (SRH139/2019). All procedures performed in studies involving human participants were in accordance with the 1964 Helsinki declaration and its later amendments or comparable ethical standards. Verbal and written informed consents were obtained from all participants.

\section{Sample size determination and sampling procedure}

The sample size was determined using Cochran's Sample Size Formula following these assumptions: $95 \%$ significance level, $5 \%$ margin of error, consumption of supplements from a previous survey being $70 \%$ according to the last Demographic and Health Survey conducted in the country [9]. The calculated sample size provided a total of 323 participants. Overall, 330 participants were recruited over a period of 12 weeks, and each regional sample size was proportionate to the estimated number of ANC service users in the regions.

\section{Data collection tool}

A researcher-developed structured questionnaire was used as the study tool. The tool was developed in English, later translated to Swazi, and back to English to ensure consistency. After developing the questionnaire based on the literature review, two experts in the field of maternal and child health from Eswatini, who were well informed about the local context, reviewed the questionnaire and gave feedback. The tool was pre-tested at Nhlambeni Clinic in the Manzini region to ensure that pregnant women could understand the questions without difficulty.

\section{Variables measurement}

The dependent variable, which was the consumption of IFA, was categorized into two categories: good and poor. Consumption of IFA was self-reported. Participants were asked if they took the supplements received in each of the three trimesters, and their responses were as follows: took all/almost all, took more than half, took half, took less than half, took a few, did not take, and not applicable (for participants who did not receive the supplements). Consuming all or almost all was categorized as good, and all the other response options were categorized as poor in each trimester. For overall consumption, participants were categorized as a good consumer if they had good consumption in all three trimesters and as a poor consumer if they had poor consumption in at least one trimester. Independent variables included sociodemographic characteristics (see Table 1 for the list of variables), knowledge, attitude, partner's support, and barriers to IFA consumption. Partner's support was measured using the question, "Do you receive support other than money from your spouse/partner?" with a fivepoint Likert scale (never, almost never, sometimes, almost always, every time).

\section{Knowledge}

Participants were asked to list three sources of iron and three sources of folate, to state the correct timing of starting IFA supplementation, and to list three benefits of taking IFA supplements and three consequences of not taking IFA supplements during pregnancy. An individual's responses to all the questions were added to form a sum of knowledge scores. The score ranged from 0 to 13 , with a higher score indicating better knowledge. Internal consistency assessed using Cronbach's alpha was 0.82 . 
Table 1 Participants' characteristics based on overall consumption of iron and folic acid during pregnancy $(N=330)$

\begin{tabular}{|c|c|c|c|c|c|c|}
\hline \multirow[t]{2}{*}{ Characteristics } & \multirow{2}{*}{$\begin{array}{l}\text { Total } \\
\text { n (\%) }\end{array}$} & & \multicolumn{2}{|l|}{ Iron } & Folic acid & \multirow[b]{2}{*}{$\begin{array}{l}\text { Poor } \\
\text { n (\%) }\end{array}$} \\
\hline & & & $\begin{array}{l}\text { Good } \\
\text { n (\%) }\end{array}$ & $\begin{array}{l}\text { Poor } \\
\text { n (\%) }\end{array}$ & $\begin{array}{l}\text { Good } \\
\text { n (\%) }\end{array}$ & \\
\hline Age, years & & & & * & & \\
\hline $18-24$ & 139 & $(42.1)$ & $3(13.6)$ & $136(44.2)$ & $6(23.1)$ & $133(43.8)$ \\
\hline $25-30$ & 101 & (30.6) & $10(45.5)$ & $91(29.5)$ & $10(38.5)$ & $91(29.9)$ \\
\hline$\geq 31$ & 90 & $(27.3)$ & $9(40.9)$ & $81(26.3)$ & $10(38.5)$ & $80(26.3)$ \\
\hline \multicolumn{7}{|l|}{ Marital status } \\
\hline Single & 167 & $(50.6)$ & $8(36.4)$ & $159(51.6)$ & $10(38.5)$ & $157(51.6)$ \\
\hline Married but not living together & 31 & $(9.4)$ & $4(18.2)$ & $27(8.8)$ & $5(19.2)$ & $26(8.6)$ \\
\hline Married and living together & 132 & $(40.0)$ & $10(45.5)$ & $122(39.6)$ & $11(42.3)$ & $121(39.8)$ \\
\hline Education & & & & $* *$ & & $* *$ \\
\hline Primary and below & 69 & $(20.9)$ & $3(13.6)$ & $66(21.4)$ & $3(11.5)$ & $66(21.7)$ \\
\hline Secondary/high school & 214 & $(64.8)$ & $9(40.9)$ & 205 (66.6) & $14(53.8)$ & $200(65.8)$ \\
\hline Tertiary & 47 & $(14.2)$ & $10(45.5)$ & $37(12.0)$ & $9(34.6)$ & $38(12.5)$ \\
\hline \multicolumn{7}{|l|}{ Religion } \\
\hline Christian & 288 & $(87.3)$ & $17(77.3)$ & $271(88.0)$ & $20(76.9)$ & $268(88.2)$ \\
\hline Other/non-religious & 42 & (12.7) & $5(22.7)$ & $37(12.0)$ & $6(23.1)$ & $36(11.8)$ \\
\hline \multicolumn{7}{|l|}{ Income } \\
\hline Sufficient/very sufficient & 130 & $(39.4)$ & $13(59.1)$ & $117(38.0)$ & $12(46.2)$ & $118(38.8)$ \\
\hline Barely sufficient & 71 & $(21.5)$ & $4(18.2)$ & $67(21.8)$ & $6(23.1)$ & $65(21.4)$ \\
\hline Insufficient/very insufficient & 129 & (39.1) & $5(22.7)$ & $124(40.3)$ & $8(30.8)$ & $121(39.8)$ \\
\hline Employment status & & & & * & & \\
\hline Unemployed & 234 & (70.9) & $9(40.9)$ & $225(73.1)$ & $14(53.8)$ & $220(72.4)$ \\
\hline Self employed & 28 & $(8.5)$ & $3(13.6)$ & $25(8.1)$ & $3(11.5)$ & $25(8.2)$ \\
\hline Employed & 68 & (20.6) & $10(45.5)$ & $58(18.8)$ & $9(34.6)$ & $59(19.4)$ \\
\hline \multicolumn{7}{|l|}{ Place of residence } \\
\hline Urban & 111 & (33.6) & $11(50.0)$ & $100(32.5)$ & $13(50.0)$ & $98(32.2)$ \\
\hline Rural & 219 & $(66.4)$ & $11(50.0)$ & $208(67.5)$ & $13(50.0)$ & $206(67.8)$ \\
\hline \multicolumn{7}{|l|}{ Gravidity } \\
\hline Primigravidity & 114 & $(34.5)$ & $9(40.9)$ & $105(34.1)$ & $11(42.3)$ & $103(33.9)$ \\
\hline Multi/Grand-multi gravidity & 216 & $(65.5)$ & $13(59.1)$ & $203(65.9)$ & $15(57.7)$ & $201(66.1)$ \\
\hline Gestational age at first ANC & & & & $* *$ & & * \\
\hline 0-12 weeks & 75 & (22.7) & $22(100)$ & $53(17.2)$ & $26(100.0)$ & $49(16.1)$ \\
\hline 13-20 weeks & 148 & $(44.8)$ & $0(0.0)$ & $148(48.1)$ & $0(0.0)$ & $148(48.7)$ \\
\hline$>20$ weeks & 107 & $(32.4)$ & $0(0.0)$ & $107(34.7)$ & $0(0.0)$ & $107(35.2)$ \\
\hline Having a supportive partner & & & & $*$ & & * \\
\hline Never/rarely & 38 & $(11.5)$ & $0(0.0)$ & $38(12.3)$ & $0(0.0)$ & $38(12.5)$ \\
\hline Sometimes & 44 & $(13.3)$ & $0(0.0)$ & $44(14.3)$ & $1(3.8)$ & $43(14.1)$ \\
\hline \multirow[t]{2}{*}{ Always/almost always } & 248 & $(75.2)$ & $22(100.0)$ & $226(73.4)$ & $25(96.2)$ & $223(73.4)$ \\
\hline & & & Mean (SD) & Mean (SD) & Mean (SD) & Mean (SD) \\
\hline Attitudes & & & $22.45(1.77)$ & $19.07(3.11)$ & $21.88(1.97)$ & $19.07(3.14)$ \\
\hline Barriers & & & $0.86(1.05)$ & $2.02(1.08)$ & $0.65(0.69)$ & $1.56(1.22)$ \\
\hline Knowledge & & & $8.23(3.27)$ & $5.46(2.81)$ & $7.92(3.12)$ & $5.45(2.81)$ \\
\hline
\end{tabular}

*indicates $p$ values $<0.05$ and ** indicates $p$ values $<0.001$ from chi-squared tests. ANC antenatal care; SD standard deviation 


\section{Attitudes}

The attitudes were assessed using five items with a Likert scale ranging from 1 to 5 . Positive statements were coded as 1 for strongly disagree and 5 for strongly agree, and negative statements were reversely coded. Items were then added to compute a sum of scores, with a score ranging from 5 to 25, with a higher score indicating more positive attitudes toward IFA supplementation. Internal consistency assessed using Cronbach's alpha for the attitude scale was 0.63 .

\section{Barriers}

Participants were asked about their reasons for not having a $100 \%$ IFA consumption in their pregnancy. Different reasons (10 reasons) for not consuming IFA were listed, and these reasons were summed up to compute a barrier score. The sum of scores ranged from 0 to 10 , with a higher score indicating more barriers for that participant.

\section{Data analyses}

Data analyses were performed using SPSS version 24 (IBM Corp, Armonk, NY). Descriptive analysis was performed to determine the prevalence of consumption of IFA supplements. The distribution of variables was evaluated using means and their standard deviations for continuous variables and proportions for categorical variables. Multivariate logistic regression was used for determining factors associated with the consumption of IFA supplements, with the odds ratio (OR) as the measure of association. A two-sided p-value of $<0.05$ was considered statistically significant. For the selection of the model, the Akaike information criterion (AIC) was used, and the smallest AIC value represented a better fitting model. We used a stepwise method and started model building by entering all variables in the model, then dropping one variable with the greatest $\mathrm{p}$-value at each step until all remaining variables were significant in the model. Goodness of fit of the final model was examined by the Hosmer-Lemeshow test $(p>0.05)$.

\section{Results}

\section{Participants' characteristics}

Of the 330 participants, a majority (42.1\%) aged 18-24 years, $50.6 \%$ of the participants reported being single on their marital status, $70.9 \%$ were unemployed, and more than half $(66.4 \%)$ resided in rural areas. Less than half $(34.5 \%)$ of them were primigravidas. Only $22.7 \%$ of the participants started their ANC visits within their first trimester, and $11.5 \%$ of the participants reported that they rarely or never received support from their partners (Table 1).

\section{Consumption of IFA supplements}

The consumption of IFA supplements by pregnant women is presented in Table 2. Good consumption was when the respondent consumed all or almost all supplements. During the first trimester, a few respondents (10\%) consumed all or almost all IFA supplements. In the second and third trimesters, those who consumed all or almost all supplements were 37 and $39.7 \%$, respectively, for iron and 37.6 and $40.9 \%$, respectively, for folic acid, which shows an increase in the consumption of both supplements from the first trimester. Women who did not receive IFA supplements owing to a lack of access were classified as not applicable (N/A). N/A in the first trimester was mainly because participants did not attend ANC in the first trimester; N/A in the second and third trimesters was owing to a lack of supply, as some facilities could not supply, and other participants were also failing to attend ANC on the dates they were booked for. When observing the overall consumption, those respondents who consumed supplements as required (i.e., all or almost all) in all three trimesters, the consumption was found to be good at 6.7 and $7.9 \%$ for iron and folic acid supplements, respectively.

\section{Factors associated with the consumption of IFA Barriers}

There was a wide range of reasons for not consuming IFA (Table 3$)$. The most frequently cited reasons were side effects $(27.5 \%)$ and forgetfulness $(25.2 \%)$. The mean number of barriers reported was 1.49 (standard deviation (SD), 1.21). Women who reported good consumption of IFA reported fewer barriers than women who reported poor consumption (mean (SD): 0.86 (1.05) vs. 2.02 (1.08) for iron; 0.65 (0.69) vs. 1.56 (1.22) for folate; both $p<0.001)$.

\section{Knowledge}

Participants had limited knowledge regarding IFA (Table 4). When asked to name three food sources of iron and folic acid, $61.5 \%$ of respondents knew at least two food sources of iron, while only $23.9 \%$ of respondents knew at least two food sources of folate. When asked about the correct time to start taking IFA supplements, only $35.8 \%$ responded correctly. When asked about the three benefits of taking the supplements, approximately $38.2 \%$ of the respondents gave at least two correct benefits. For the consequences of not taking IFA supplements during pregnancy, only $21.6 \%$ could give at least two correct consequences. The mean knowledge score was 5.65 (2.91). Women who reported good consumption of IFA reported a higher knowledge than those who reported poor consumption (mean (SD): 8.23 (3.27) vs. 5.46 (2.81) for iron; 7.92 (3.12) vs. 5.45 (2.81) for folate; both $p<0.001)$. 
Table 2 Consumption of iron and folic acid supplements over the three trimesters of pregnancy $(N=330)$

\begin{tabular}{|c|c|c|c|c|c|c|}
\hline & \multicolumn{3}{|c|}{ Consumption of iron } & \multicolumn{3}{|c|}{ Consumption of folic acid } \\
\hline & 1st trimester & 2nd trimester & 3rd trimester & 1st trimester & 2nd trimester & 3rd trimester \\
\hline All/almost all & $34(10.3)$ & $122(37.0)$ & $131(39.7)$ & $34(10.3)$ & $124(37.6)$ & $135(40.9)$ \\
\hline More than half & $15(4.5)$ & $67(20.3)$ & $67(20.3)$ & $14(4.2)$ & $57(17.3)$ & 69 (20.9) \\
\hline Half & $7(2.1)$ & $38(11.5)$ & $38(11.5)$ & $4(1.2)$ & $39(11.8)$ & $33(10.0)$ \\
\hline Less than half & $7(2.1)$ & $32(9.7)$ & $36(10.9)$ & $10(3.0)$ & $32(9.7)$ & $33(10.0)$ \\
\hline Did not consume or consumed a few & $6(1.8)$ & $23(7.0)$ & $40(12.1)$ & $9(2.7)$ & $31(9.4)$ & $43(13.0)$ \\
\hline N/A & $261(79.1)$ & $48(14.5)$ & $18(5.5)$ & $259(78.5)$ & $47(14.2)$ & $17(5.2)$ \\
\hline
\end{tabular}

N/A is not applicable, meaning women who cannot access iron and folic acid supplements. N/A refers to participants who did not attend antenatal care or did not receive the supply in facilities owing to limited stock

\section{Attitude}

Participants' attitudes are presented in Table 5. The mean attitude score was 19.29 (3.16). Over $40 \%$ (43.1\%) of women strongly agreed or agreed that "consuming IFA could result in macrosomia”, and about $10 \%(9.1 \%)$ of women strongly agreed or agreed that IFA should be consumed only when there is a problem. Those women who reported good consumption of IFA reported better attitude than those who reported poor consumption (mean (SD): 22.45 (1.77) vs. 19.07 (3.11) for iron; 21.88 (1.97) vs. 19.07 (3.14) for folate; both $p<0.001)$.

\section{Bivariate analysis}

The bivariate analysis of different variables with the overall consumption status is presented in Table 1 . The status of iron consumption in all trimesters significantly differed by age, education, and employment status. However, the status of folic acid consumption significantly differed by education and gestational age at the first ANC visit. Participants with good consumption of both

Table 3 Participants' reasons for not consuming iron and folic acid supplements $(\mathrm{N}=330)$

\begin{tabular}{lll}
\hline Reasons & $\mathbf{n}$ & $\%$ \\
\hline Long walking distance to health facility & 27 & 8.2 \\
Transport costs & 40 & 12.1 \\
Safe previous pregnancies without iron and folic acid & 56 & 17.0 \\
supplements & 54 & 16.4 \\
Advised by friends/relatives not to consume & 34 & 10.3 \\
Use of traditional medicine & 83 & 25.2 \\
Forgetfulness & 89 & 27.0 \\
Side effects & 34 & 10.3 \\
Inadequate supply & \\
Tablets were out of stock in facility & 47 & 14.2 \\
Dislike medication & 27 & 8.2 \\
Number of barriers; Mean (SD) & 1.49 \\
\end{tabular}

Number of barriers score range: $0-10$. A high total score indicates more barriers. ${ }^{a}$ Inadequate supply: cases where participants were supplied with pills not covering the period up to next visit. SD standard deviation iron and folic acid started attending ANC within the first 12 weeks of their pregnancy. Out of the participants who were classified as poor consumers of iron, only $17.2 \%$ started attending ANC within the first 12 weeks of their pregnancy. From the poor consumers of folic acid, only $16.1 \%$ started attending ANC within the first 12 weeks of their pregnancy. Participants with good consumption of IFA were significantly more likely to report that their partner was always or almost always supportive than participants with poor consumption (100\% vs. $73.4 \%$ for iron; $96.2 \%$ vs. $73.4 \%$ for folic acid).

\section{Multivariate analysis}

The parsimonious logistic regression model is presented in Table 6. The likelihood of consuming iron over the three trimesters increased with age. Using the age of 1824 years as a comparison group, the odds of iron consumption for those aged 25-30 years were 2.92 (95\% confidence interval (CI): 0.71-12.06), and the odds for the group aged above 30 years were 4.44 (95\% CI: 1.0918.10). An increase in the score of IFA knowledge was associated with good iron consumption (adjusted OR (AOR): 1.23, $95 \%$ CI: 1.05-1.44), and similarly, an increase in the score of attitudes was associated with good iron consumption (AOR: 1.41, 95 \% CI: 1.13-1.75). Having barriers was a significant factor, and as the score of barriers increased, the likelihood of consuming iron decreased (AOR: 0.53, 95 \% CI: 0.29-0.97).

Table 6 illustrates that when a similar analysis was performed for folic acid consumption in the three trimesters, having a unit increase in the total score of knowledge about IFA was significantly associated with good consumption of folic acid supplements in the three trimesters (AOR: 1.24, 95 \% CI 1.07-1.43). Table 6 also demonstrates that having barriers was a significant factor, and as the score of barriers increased, the likelihood of consuming folic acid decreased (AOR: 0.51, $95 \% \mathrm{CI}$ : 0.31-0.89). Attitude lost its statistical significance when knowledge and barriers were in the model for folic acid. 
Table 4 Distribution of participants' responses about knowledge $(N=330)$

\begin{tabular}{|c|c|c|c|c|c|c|}
\hline \multirow[b]{2}{*}{ Variables } & \multicolumn{2}{|c|}{ Total } & \multicolumn{2}{|c|}{ Iron consumption } & \multicolumn{2}{|c|}{ Folate consumption } \\
\hline & n & (\%) & Good $(n=22)$ & Poor $(n=308)$ & Good $(n=26)$ & Poor $(n=304)$ \\
\hline \multicolumn{7}{|c|}{ A list of three food items that are a good source of iron. } \\
\hline All three responses correct & 91 & $(27.6)$ & $10(45.5)$ & $81(26.3)$ & $11(42.3)$ & $80(26.3)$ \\
\hline Only two correct responses & 112 & $(33.9)$ & $9(40.9)$ & $103(33.4)$ & $10(38.5)$ & $102(33.6)$ \\
\hline Only one correct response & 91 & $(27.6)$ & $2(9.1)$ & 89 (28.9) & $4(15.4)$ & 87 (28.6) \\
\hline No correct response & 36 & $(10.9)$ & $1(4.5)$ & $35(11.4)$ & $1(3.8)$ & $35(11.5)$ \\
\hline \multicolumn{7}{|c|}{ A list of three food items that are a good source of folate. } \\
\hline All three responses correct & 36 & $(10.9)$ & $4(18.2)$ & $32(10.4)$ & $5(19.2)$ & $31(10.2)$ \\
\hline Only two correct responses & 43 & $(13.0)$ & $3(13.6)$ & $40(13.0)$ & $4(15.4)$ & $39(12.8)$ \\
\hline Only one correct response & 186 & $(56.4)$ & $11(50.0)$ & $175(56.8)$ & $13(50.0)$ & $173(56.9)$ \\
\hline No correct response & 65 & $(19.7)$ & $4(18.2)$ & $61(19.8)$ & $4(15.4)$ & $61(20.1)$ \\
\hline \multicolumn{7}{|c|}{ When should a pregnant woman start consuming IFA supplements? } \\
\hline Correct response & 118 & $(35.8)$ & $16(72.7)$ & $102(33.1)$ & $18(69.2)$ & $100(67.1)$ \\
\hline Incorrect response & 212 & $(64.2)$ & $6(27.3)$ & $206(66.9)$ & $8(30.8)$ & $204(32.9)$ \\
\hline \multicolumn{7}{|c|}{ A list of three benefits of consuming IFA supplements during pregnancy. } \\
\hline All three responses correct & 34 & $(10.3)$ & $9(40.9)$ & $25(8.1)$ & $8(30.8)$ & $26(8.6)$ \\
\hline Only two correct responses & 92 & $(27.9)$ & $5(22.7)$ & $87(28.2)$ & $9(34.6)$ & $83(27.3)$ \\
\hline Only one correct response & 146 & $(44.2)$ & $6(27.3)$ & $140(45.5)$ & $7(26.9)$ & $139(45.7)$ \\
\hline No correct response & 58 & $(17.6)$ & $2(9.1)$ & $56(18.2)$ & $2(7.7)$ & $56(18.4)$ \\
\hline \multicolumn{7}{|c|}{ A list of three consequences of not consuming IFA supplements during pregnancy } \\
\hline All three responses correct & 19 & (5.8) & $8(36.4)$ & $11(3.6)$ & $7(26.9)$ & $12(3.9)$ \\
\hline Only two responses correct & 52 & $(15.8)$ & $6(27.3)$ & $46(14.9)$ & $7(26.9)$ & $45(14.8)$ \\
\hline Only one correct response & 185 & $(56.1)$ & $7(31.8)$ & $178(57.8)$ & $11(42.3)$ & $174(57.2)$ \\
\hline No correct response & 74 & $(22.4)$ & $1(4.5)$ & $73(23.7)$ & $1(3.8)$ & $73(24.0)$ \\
\hline Knowledge scores; Mean (SD) & \multicolumn{6}{|c|}{$5.65(2.91)$} \\
\hline
\end{tabular}

Score range: 1-13. A higher score indicates better knowledge. IFA iron and folic acid supplements; SD standard deviation

\section{Discussion}

Our results showed that the overall good consumption of IFA supplements throughout pregnancy in Eswatini was approximately 7 and $8 \%$ for iron and folic acid supplements, respectively. The overall adherence rate to iron supplementation across 22 Sub-Saharan African (SSA) countries (excluding Eswatini) was $28.7 \%$ and ranged from $1.4 \%$ in Burundi to $73.0 \%$ in Senegal [14].
This consumption pattern is still relatively low than that in other countries, such as South Africa, where compliance with the consumption of IFA supplements was reported to be $93 \%$ among pregnant women [26]. Another African country with a higher consumption rate is Kenya, with compliance to IFA at approximately $80 \%$ [23]. The adherence to IFA supplementation was $28.7 \%$ in Ethiopia [24], which was similar to this study in which

Table 5 Distribution of participants' responses about attitude $(N=330)$

\begin{tabular}{llllll}
\hline Attitudes & $\begin{array}{l}\text { Strongly agree } \\
\mathbf{n}(\%)\end{array}$ & $\begin{array}{l}\text { Agree } \\
\mathbf{n}(\%)\end{array}$ & $\begin{array}{l}\text { Not sure } \\
\mathbf{n}(\%)\end{array}$ & $\begin{array}{l}\text { Disagree } \\
\mathbf{n}(\%)\end{array}$ & $\begin{array}{l}\text { Strongly disagree } \\
\mathbf{n}(\%)\end{array}$ \\
\hline IFA is good for fetus & $134(40.6)$ & $179(54.2)$ & $17(5.2)$ & $0(0.0)$ & $0(0.0)$ \\
Pregnant women should adhere to IFA & $122(37.0)$ & $112(33.9)$ & $90(27.3)$ & $6(1.8)$ & $0(0.0)$ \\
Consuming IFA could result in fetal macrosomia & $85(25.8)$ & $57(17.3)$ & $94(28.5)$ & $28(8.5)$ & $66(20.0)$ \\
IFA could result in unsuccessful pregnancies & $4(1.2)$ & $4(1.2)$ & $73(22.1)$ & $74(22.4)$ & $175(53.0)$ \\
IFA should be taken only when there is a problem & $6(1.8)$ & $24(7.3)$ & $92(27.9)$ & $105(31.8)$ & $103(31.2)$ \\
Attitudes' sum of score; Mean (SD) & $19.29(3.16)$ & & & &
\end{tabular}


Table 6 Logistic regression models of factors associated with good IFA consumption during pregnancy $(N=330)$

\begin{tabular}{|c|c|c|c|c|c|c|}
\hline \multicolumn{4}{|l|}{ Good iron consumption } & \multicolumn{3}{|c|}{ Good folic acid consumption } \\
\hline Explanatory variables & AOR & $95 \% \mathrm{Cl}$ & $p$-value & AOR & $95 \% \mathrm{Cl}$ & $p$-value \\
\hline Age & & & & NS & & \\
\hline $18-24$ & 1.00 & & & & & \\
\hline $25-30$ & 2.92 & $(0.71-12.06)$ & 0.14 & & & \\
\hline 31 and above & 4.44 & $(1.09-18.10)$ & $0.04^{*}$ & & & \\
\hline Knowledge & 1.23 & $(1.05-1.44)$ & $0.001^{*}$ & 1.24 & $(1.07-1.43)$ & $0.004^{*}$ \\
\hline Attitude & 1.41 & $(1.13-1.75)$ & $<0.002^{*}$ & NS & & \\
\hline Barriers & 0.53 & $(0.29-0.97)$ & $0.04^{*}$ & 0.51 & $(0.31-0.89)$ & $0.02^{*}$ \\
\hline
\end{tabular}

NS not statistically significant and was not included in the model; IFA iron and folic acid; $A O R$ adjusted odds ratio; $C l$ confidence interval. ${ }^{*} P<0.05$

the consumption was $<50 \%$. It was noted that the numbers might not be directly comparable since the measurement of adherence or good consumption varied across studies. Nonetheless, IFA supplementation for pregnant women in Eswatini needs to be further advocated.

Despite the low rate of good consumption of IFA supplementation throughout all trimesters of pregnancy, we found that the rate of good consumption increased from $10 \%$ in the first trimester to approximately $40 \%$ in the second and third trimesters. The low rate of good consumption of IFA supplements throughout pregnancy was mainly owing to late ANC booking, and thus, late commencement of IFA consumption since only $23 \%$ of the participants booked ANC within their first trimester. It was noted that approximately 14 and $5 \%$ of participants did not adhere to the consumption of IFA supplements in the second and third trimester, respectively, because they did not attend ANC or did not receive the supply in facilities due to limited stock. IFA consumption increased to $46 \%$ in our participants during the second and third trimesters after those who did not receive IFA were excluded (data not shown). Thus, ANC in the first trimester should be emphasized, and supplies of IFA supplements in facilities should be better managed.

Participants' age was found to be associated with iron consumption in our study, which is consistent with other studies [14, 26]. Ba and colleagues suggested that the positive association between age and adherence to iron supplementation during pregnancy could be explained by older women's understanding of the benefits of iron supplementation for preventing anemia or having previously experienced iron deficiency-related adverse outcomes [14].

A positive association was observed between positive attitudes and consumption of IFA in our study. Strong agreement that IFA supplementation is good for the fetus was observed in $40.6 \%$ of the participants, whereas negative attitude, such as strong agreement that IFA supplementation results in fetal macrosomia, was observed in $25.8 \%$ of the study participants. Similarly, the beliefs that the supplement tablets would harm the baby were found to be significantly associated with noncompliance to IFA consumption in the Mecha district, Ethiopia [27]. The major barrier, associated with the lower consumption of IFA supplements, was the side effects, which was also listed in other studies as a major obstacle for the consumption and compliance [28, 29]. Therefore, it is recommended that healthcare workers in the facilities correct misconceptions about IFA consumption and instruct women on how to manage the potential side effects of IFA supplementation.

In our study, knowledge of IFA supplements was significantly associated with the consumption of folic acid supplements in the second and third trimesters. A similar finding was observed in Kenya, where the authors concluded that knowledge of IFA among pregnant women was associated with improved compliance [30]. Knowledge was significantly associated with compliance to prenatal IFA supplementation among women in Mecha, Ethiopia [27]. In another study in Northwest Ethiopia, knowledge about the benefits of supplements was associated with IFA supplementation adherence among pregnant women [31]. Based on the previous literature and our findings, we assume that informed pregnant women are more likely to consume adequate supplementation because they have been empowered, and they understand the benefits that come with supplementation.

Our study results should be acknowledged within the following limitations. The selection bias was possible, since the study participants were pregnant women attending antenatal care at eight healthcare facilities, which is not a random sample of pregnant women and may not represent pregnant women in Eswatini. Those women who used antenatal care may be more likely to take IFA than those who did not. Owing to the crosssectional nature of the study, the associated factors were correlational rather than causal. The exclusion of women aged $<18$ years limited the generalizability of our findings to all pregnant women and prevented the identification of factors that may be unique to this age group. 
However, these factors may be crucial when developing strategies to improve the consumption of IFA by all pregnant women. There is a possibility of recall bias since participants were asked about their consumption patterns from the first trimester to the third trimester. There is also a possibility that some of the participants were reporting what they deemed socially acceptable and reporting about pills that they did not ingest.

\section{Conclusions}

In summary, IFA supplement consumption among pregnant women is poor in Eswatini, despite IFA supplementation being included as part of the ANC package. It is evident that most women still lack knowledge, and some have negative attitudes regarding IFA supplements. The findings show that side effects, forgetfulness, safe previous pregnancies without IFA, others' advice against consumption, IFA stock-outs, inability to meet transport costs, and inadequate supply of IFA tablets are barriers to adherence to IFA supplement consumption. To improve consumption, strategies such as establishing a preconception care unit and school-based provision of IFA supplements may be helpful. Multiple strategies need to be employed to overcome the identified barriers. These strategies may include community health care workers for distributing IFA supplements, discussing with clients about the measures to reduce forgetfulness, advising ways to prevent and manage the side effects, providing subsidies to cover transport costs, and ensuring adequate supply of IFA supplements in facilities. To address the negative attitudes and lack of knowledge, known accurate information should be revisited and reinforced in health education, myths should be dispelled, and the importance of IFA supplementation should be intensified.

\section{Abbreviations}

IFA: Iron and folic acid; ANC: Antenatal care; WHO: World Health Organization; SD: Standard deviation; AOR: Adjusted odds ratio; AIC: Akaike information criterion; Cl: Confidence interval

\section{Acknowledgements}

Gratitude was extended to the participants and health facilities' staff members for their support and cooperation during data collection.

\begin{abstract}
Authors' contributions
GNM conceived the idea, proposed the study, developed the tool, collected and captured the data, performed the analysis, interpreted the data, and wrote the manuscript. LYC assisted with proposal writing, tool development, and provided guidance on analysis and manuscript review. AW and ON contributed to the analysis and manuscript review. The author(s) read and approved the final manuscript.
\end{abstract}

\section{Funding}

The National Yang-Ming University through the International Health Program office provided funding for air travel from Taiwan (Taipei) to Eswatini. All other expenses were self-funded.

\section{Declarations}

\section{Ethics approval and consent to participate}

The study was approved by the National Health Research Review Board, Ministry of Health, in Eswatini. The protocol reference number is SHR139/ 2019. Verbal and written consent was obtained from participants after receiving a full description of the study.

Consent for publication

Not applicable.

\section{Competing interests}

The authors declare that they have no competing interests.

\section{Author details}

${ }^{1}$ International Health Program, National Yang Ming Chiao Tung University, 155 Li-Nong Street, Section 2, Bei-Tou, 11221 Taipei, Taiwan. ${ }^{2}$ Institute of Public Health, National Yang Ming Chiao Tung University, Taipei, Taiwan. ${ }^{3}$ Taoyuan General Hospital, Ministry of Health and Welfare, Taoyuan, Taiwan. ${ }^{4}$ Institute of Health and Wellbeing, University of Glasgow, Glasgow, UK. ${ }^{5}$ Institute of Community Health Care, College of Nursing, National Yang Ming Chiao Tung University, 155 Li-Nong Street, Section 2, 11221 Taipei, Taiwan.

Received: 28 January 2021 Accepted: 12 May 2021

Published online: 30 June 2021

\section{References}

1. Picciano MF. Pregnancy and lactation: physiological adjustments, nutritional requirements and the role of dietary supplements. J Nutr. 2003;133(6): 1997S-2002S.

2. Wardlaw GM, Hampl JS, Di Sivelstro RA. Perspectives in Nutrition. 6th Ed. ed. New York: McGraw Hill Companies, Inc.; 2007.

3. Meyers LD, Hellwig JP, Otten JJ. Dietary reference intakes: the essential guide to nutrient requirements: National Academies Press; 2006. https:// www.nal.usda.gov/sites/default/files/fnic_uploads/DRIEssentialGuideNutReq. pdf. Accessed 27th January, 2021

4. Zhu H, Kartiko S, Finnell R. Importance of gene-environment interactions in the etiology of selected birth defects. Clin Genet. 2009;75(5):409-23.

5. Murugan R. Determinants of Adherence to Iron Folic Acid Supplementation among Pregnant Women Attending Antenatal Clinic in Asella Town, Ethiopia. Int J Ther Appl. 2018;35.

6. WHO. The global prevalence of anaemia in 20112015 04/04/2019. Available from: https://www.who.int/nutrition/publications/micronutrients/global_ prevalence_anaemia_2011/en/. Accessed 27th January, 2021.

7. Ali AA, Rayis DA, Abdallah TM, Elbashir MI, Adam I. Severe anaemia is associated with a higher risk for preeclampsia and poor perinatal outcomes in Kassala hospital, eastern Sudan. BMC Res Notes. 2011:4:311-.

8. Birhanu TM, Birarra MK, Mekonnen FA. Compliance to iron and folic acid supplementation in pregnancy, Northwest Ethiopia. BMC Res Notes. 2018; 11(1):345-.

9. Central Statistical Office [Swaziland] and Macro International. Swaziland Demographic and Health Survey 2006-07: Key Findings.; 2008. https:// dhsprogram.com/pubs/pdf/SR138/SR138.pdf. Accessed 27th January, 2021.

10. CSO. Swaziland Multiple Indicator Cluster Survey 2014, Key Findings. Mbabane, Swaziland; 2015. https://mics-surveys-prod.s3.amazonaws.com/ MICS5/Eastern\%20and\%20Southern\%20Africa/Eswatini/2014/Key\%2 Ofindings/Swaziland\%202014\%20MICS\%20KFR_English.pdf. Accessed 27th January, 2021.

11. Barua S, Kuizon S, Junaid MA. Folic acid supplementation in pregnancy and implications in health and disease. J Biomed Sci. 2014;21(1):77.

12. Cogswell ME, Parvanta I, Ickes L, Yip R, Brittenham GM. Iron supplementation during pregnancy, anemia, and birth weight: a randomized controlled trial. Am J Clin Nutr. 2003;78(4):773-81.

13. Peña-Rosas JP, De-Regil LM, Garcia-Casal MN, Dowswell T. Daily oral iron supplementation during pregnancy. Cochrane Database Syst Rev 2015 Jul 22(7):CD004736.

14. Ba DM, Ssentongo P, Kjerulff KH, Na M, Liu G, Gao X, et al. Adherence to iron supplementation in 22 sub-Saharan African countries and associated factors among pregnant women: a large population-based study. Curr Dev Nutr. 2019;3(12):nzz120. 
15. Ogundipe O, Hoyo C, Østbye T, Oneko O, Manongi R, Lie RT, et al. Factors associated with prenatal folic acid and iron supplementation among 21,889 pregnant women in Northern Tanzania: a cross-sectional hospital-based study. BMC public health. 2012;12:481-.

16. Mbhenyane $X$, Cherane M. Compliance with the consumption of iron and folate supplements by pregnant women in Mafikeng local municipality, North West province, South Africa. Afr Health Sci. 2017;17(3):657-70.

17. Ibrahim Z, Abd S, Mikhail H, Sc M, Khattab M. Assessment of Adherence to Iron and Folic Acid Supplementation and Prevalence of Anemia in Pregnant Women. Med J Cairo Univ. $2014(79$ (2)):115-21.

18. Dlamini J. Vital drug for pregnant women runout. The Times of Swaziland. 2018. http://www.times.co.sz/news/121443-vital-drug-for-pregnant-womenruns-out.html. Accessed 27 January, 2021.

19. Arega Sadore A, Abebe Gebretsadik L, Aman Hussen M. Compliance with iron-folate supplement and associated factors among antenatal care attendant mothers in Misha District, South Ethiopia: community based cross-sectional study. J Environ Publicc Health. 2015;2015:781973.

20. Chourasia A, Pandey CM, Awasthi A. Factors influencing the consumption of iron and folic acid supplementations in high focus states of India. Clin Epidemiol Glob Health. 2017;5(4):180-4.

21. Gebre A, Mulugeta A, Etana B. Assessment of factors associated with adherence to iron-folic acid supplementation among urban and rural pregnant women in North Western Zone of Tigray, Ethiopia: comparative Study. Int j Food Sci Nutr. 2015;4(2):161.

22. Godara S, Hooda R, Nanda S, Mann S. To study compliance of antenatal women in relation to iron supplementation in routine ante-natal clinic at a tertiary health care centre. J drug deliv ther. 2013;3(3):71-5.

23. Maina-Gathigi L, Omolo J, Wanzala P, Lindan C, Makokha A. Utilization of folic acid and iron supplementation services by pregnant women attending an antenatal clinic at a regional referral hospital in Kenya. Matern Child Health J. 2013;17(7):1236-42.

24. Agegnehu G, Atenafu A, Dagne H, Dagnew B. Adherence to iron and folic acid supplement and its associated factors among antenatal care attendant mothers in Lay Armachiho health centers, Northwest, Ethiopia, 2017. Int J Reprod Med. 2019;2019:5863737.

25. Tsawe M, Moto A, Netshivhera T, Ralesego L, Nyathi C, Susuman AS. Factors influencing the use of maternal healthcare services and childhood immunization in Swaziland. Int J Equity Health. 2015; 14:32.

26. Mbhenyane $\mathrm{X}$, Cherane M. Compliance with the consumption of iron and folate supplements by pregnant women in Mafikeng local municipality, north west province, South Africa. Afri Health Sci. 2017;17(3):115-21.

27. Taye B, Abeje G, Mekonen A. Factors associated with compliance of prenatal iron folate supplementation among women in Mecha district, Western Amhara: a cross-sectional study. Pan Afr Med J. 2015;20(43).

28. Gebremedhin S, Samuel A, Mamo G, Moges T, Assefa T. Coverage, compliance and factors associated with utilization of iron supplementation during pregnancy in eight rural districts of Ethiopia: a cross-sectional study. BMC public Health. 2014:14:607.

29. Kiwanuka TS, Ononge S, Kiondo P, Namusoke F. Adherence to iron supplements among women receiving antenatal care at Mulago National Referral Hospital, Uganda-cross-sectional study. BMC Res notes. 2017;10(1):510.

30. Kamau M, Mirie W, Kimani S, Mugoya I. Effect of community based health education on knowledge and attitude towards iron and folic acid supplementation among pregnant women in Kiambu County, Kenya: A quasi experimental study. PLoS One. 2019;14(11):e0224361.

31. Assefa H, Abebe SM, Sisay M. Magnitude and factors associated with adherence to Iron and folic acid supplementation among pregnant women in Aykel town, Northwest Ethiopia. BMC Pregnancy Childbirth. 2019;19(1):296.

\section{Publisher's Note}

Springer Nature remains neutral with regard to jurisdictional claims in published maps and institutional affiliations.

\section{Ready to submit your research? Choose BMC and benefit from:}

- fast, convenient online submission

- thorough peer review by experienced researchers in your field

- rapid publication on acceptance

- support for research data, including large and complex data types

- gold Open Access which fosters wider collaboration and increased citations

- maximum visibility for your research: over $100 \mathrm{M}$ website views per year

At BMC, research is always in progress.

Learn more biomedcentral.com/submissions 